\title{
Fracture Reduction in Steel Cord Manufacturing Process
}

\author{
L. Prabhu, M. Natarajan, C. Thiagarajan, M. Natarajan, R. Bharathi, S. Karthick
}

\begin{abstract}
Improve quality and productivity performance of a steel cord manufacturing system. The most importuned material of steel cord for tyre manufacturing process and that steel cord have good mechanical properties of high breaking strength, and low thermal coefficient of expansion as compared to nylon. Process for producing a Steel cord for pneumatic tires comprising a bunch of wires and core, the core of which consists of 3wire filaments arranged and bunched together in parallel. Then 6 wire (filament) on Core twisted and bunched in together. While processing on steel cord we faced wire fracture frequently like torsional fracture, power fracture, one filament fracture, entanglement fracture bad winding issue due to interrupted power and improper clamping of spool (wire Bobbin) and machine vibration. In this project have modified to Spool shaft on wire drawing machine. In this shaft, locking position and changed that shaft design. That shaft was reduced the spool wobbling while running on machine. In bunching machine, the circuit have power circuit-1, power circuit-2, control circuit, and commend circuit. The command and control circuits connected by uninterrupted power and power circuits connected with normal power (EB power). When power the cut-off, command and control circuit switchover to uninterrupted power, and it lead to smooth stop in machine. Thus, the changes have leads to reduce the fracture in cord manufacturing process.
\end{abstract}

Keywords : About four key words or phrases in alphabetical order, separated by commas.

\section{INTRODUCTION}

$T_{\text {his }}$ is In steel wire transformation and coatings, a renowned company is Bekaert.

- focus on sustainable \& profitable growth.

- By implementing our worldwide market and technological leadership, strategy in the business segments and markets where we are active.

- By working for success together: with our customers, suppliers and other business partners, within our organization, and throughout the divisions and regions [1]. And regionspossible.Figure 1 it shows the spools which wire

Revised Manuscript Received on December 16, 2019

* Correspondence Author

L.Prabhu*, Assoc. Professor, Department of Mechanical Engineering, Aarupadai Veedu Institute of Technology, Vinayaka Mission Research Foundation, Chennai, India . Email: prabhu@avit.ac.in.

C.Thiagarajan, Department of Mechanical Engineering, Aarupadai Veedu Institute of Technology, Vinayaka Mission's Research Foundation, Deemed To Be University, Chennai, India.

M.Natarajan, R.Bharathi, S.Karthick, UG Student, Department of Mechanical Engineering, Aarupadai Veedu Institute of Technology, Vinayaka Mission's Research Foundation, Deemed To Be University, Chennai, India. represented on a diagram.
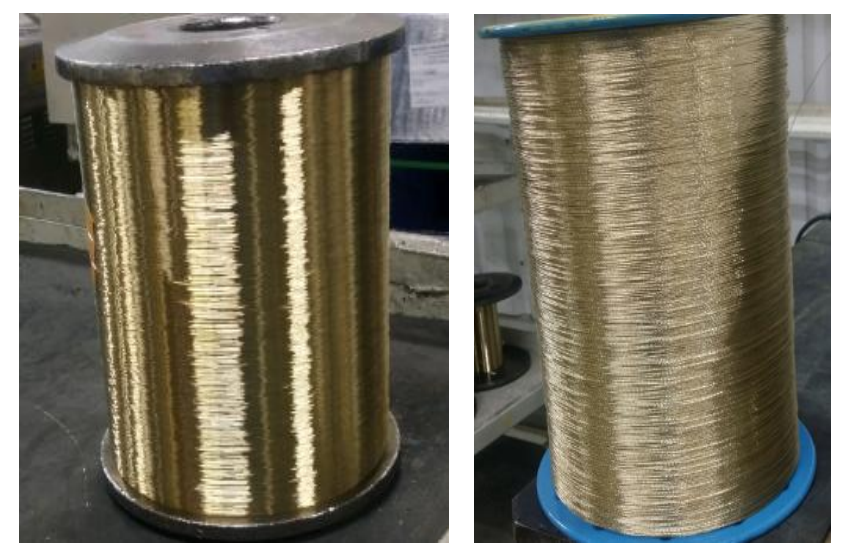

Fig. 1..Spools which wire is winded

\section{METHODOLOGY}

A. Manufacturing Process

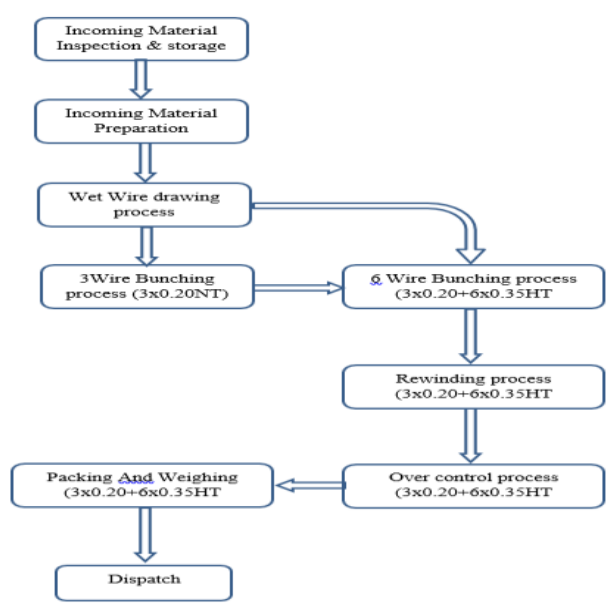

Fig. 2. Methodology

Figure 2 which represented as the incoming material prepares for drawing process. It connected to wire bunching process. Finally dispatch the material. 


\section{B. Incoming Material and Preparation}
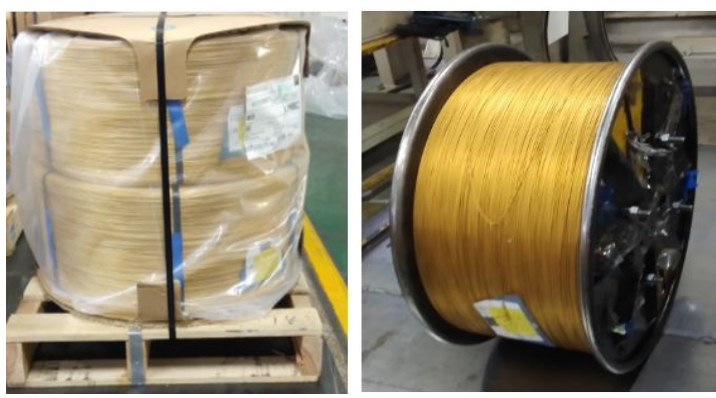

Fig. 3.Material and preparation

Figure.3 represents the Meterial and preparation used to incoming materials are prepared and through the bunching process.

\section{Wire Drawing Process}

A drawing process used to reduce the cross section of a wire by pulling the wire through a single, or series of, drawing die's figure -3 . Filament used as an individual element in a strand or cord standard, filament diameterisavailable0.15/0.175/0.20/0.22/0.27/0.28/0.30/0.3 $5 / 0.38 \mathrm{~mm}$. wrap wound helically around steel cord. Figure 4 shows the wire drawing process [2]

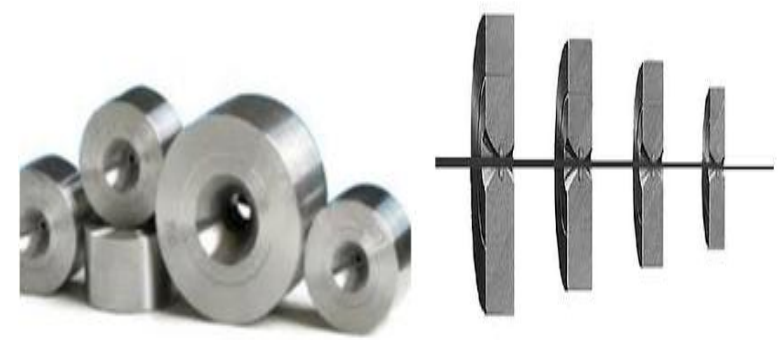

Fig. 4.Wire Drawing Process

\section{Bunching Process}

Steel cord manufactured from many grades and types of construction figuar it shows the bunching process

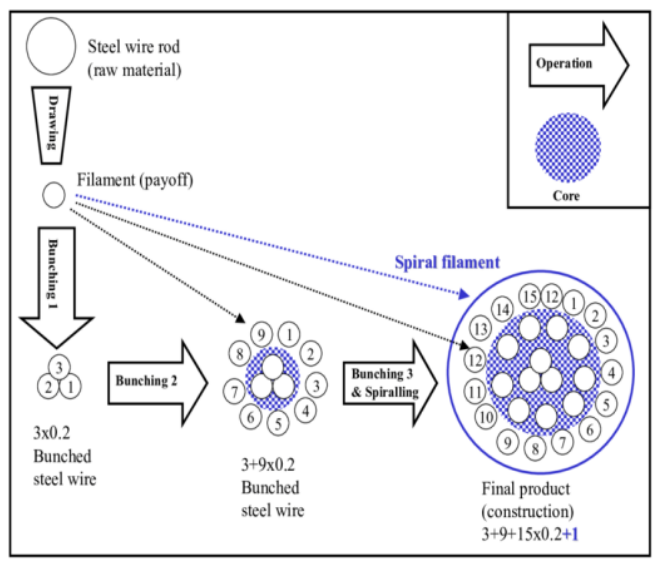

Fig. 5.Bunching Process
Figure 6 represents the steel cord types

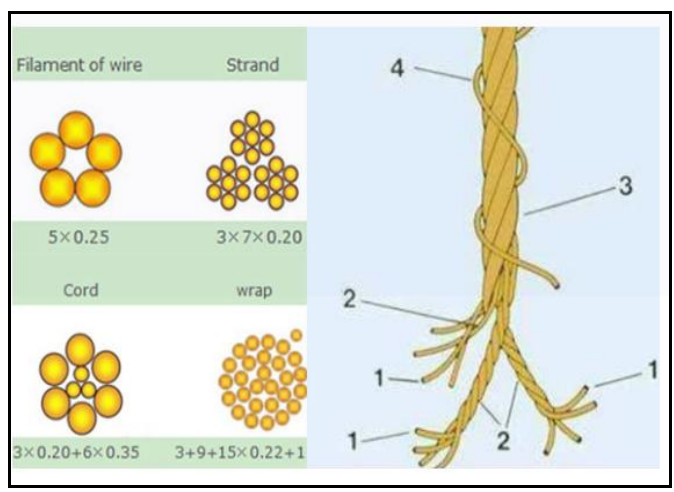

Fig. 6. Steel cord types

\section{E. Rewinding Process}

Steel cord is received from bunching machine with high quality in a spool [3]. Then the steel cord is convert to customer spool according to specification length, hear the quality parameter of torsion, length, straightness, arc height and elongation are ensured and move to over control area [4]. Figure 7 and Fiogure 8 shows the steel cord application and Fracture types.

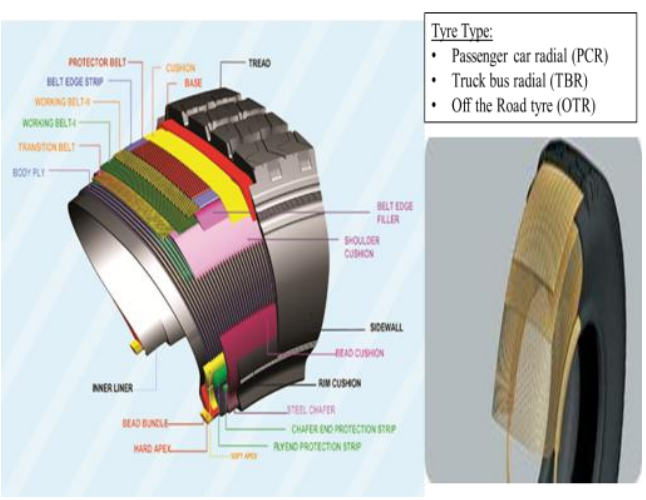

Fig. 7.Steel Cored Application

\section{Some Fracture Groups}

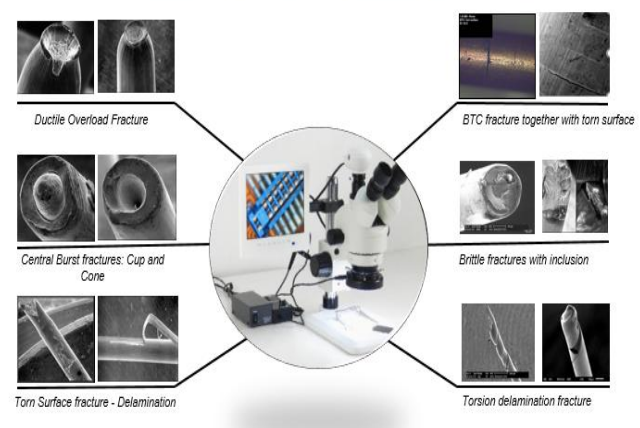

Fig. 8.Fracture Types 


\section{F. Components and Description}

1. PNEUMATIC CYLINDER (SMC- CD255B80-20)

2. 5/3 DIRECTION CONTROL VALVE

3. 5/2 Directional Control Valve

4. SHAFT

Table- II: Estimation Of Component

\begin{tabular}{|c|c|l|c|r|}
\hline \multicolumn{5}{|c|}{ Estimation of Component } \\
\hline S.No & Part code & \multicolumn{1}{|c|}{ Name } & Qty & Amount \\
\hline 1 & 2144100 & $\begin{array}{l}\text { Pneumatic } \\
\text { cylinder }\end{array}$ & 1 & 3000 \\
\hline 2 & 2144150 & Cylinder fixture & 1 & 1510 \\
\hline 3 & 2144090 & $5 / 2,24 V$ valve & 1 & 1560 \\
\hline 4 & 2144098 & Shaft V1.1.5 & 1 & 45000 \\
\hline 5 & 2144099 & Rubber ring & 2 & 300 \\
\hline 6 & 2144111 & Sleeve & 3 & 450 \\
\hline 7 & 2144123 & Spring washer & 20 & 200 \\
\hline 8 & 2144124 & Lock nut & 1 & 70 \\
\hline 9 & 2144125 & Bushing rod & 1 & 520 \\
\hline 10 & 2144008 & M12x80 mm Bolt & 4 & 80 \\
\hline 11 & 2144908 & M6x20 mm Bolt & 4 & 56 \\
\hline \multicolumn{5}{|r|}{ Total Amount } \\
\end{tabular}

\section{G. Fracture Trends}

Fractures are calculated only 3 wire bunching process only, each month we monitor and followed in [5].production KPI. In addition, it is affected in next process 6 wire bunching process because of unable to run calculated length

Formulas for Fracture per ton $=$ Total number of fracture $/$ Production volume in ton.

Figure 9 shows the pareto analysis of fracture on 3 wire bunching process

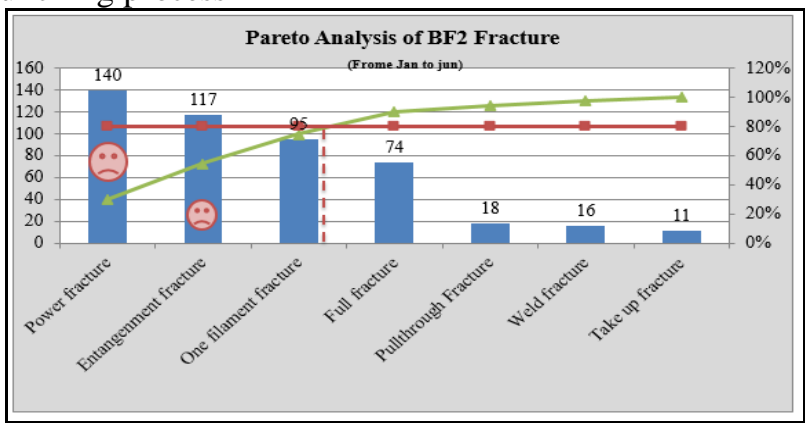

Fig. 9.Pareto Analysis of Fracture on 3 Wire Bunching Process

We know as 80/20 Pareto rule, We take action as following Power fracture,

1. Entanglement fracture,

3. One filament fracture is nothing but the fracture is happen at one input spool, it has happened due to entanglement from filament-produced machine (Drawing process), so that we select rest the fracture
2. One filament fracture

types of Power fracture and Entanglement fracture [7].

\section{RESULT AND DISCUSSION}

Figure 10 represents the fracture analysis1 power fracture

\section{EB power trips trends}

\begin{tabular}{|c|c|c|}
\hline Month & Sum of Totol Trips & Sum of Un-planned Trips \\
\hline$\boxplus \mathrm{Jan}$ & 25 & 18 \\
\hline$\exists \mathrm{Feb}$ & 20 & 13 \\
\hline$\exists \mathrm{Mar}$ & 86 & 26 \\
\hline$\pm \mathrm{Apr}$ & 70 & 26 \\
\hline$₫$ May & 18 & 14 \\
\hline$\exists$ Jun & 4 & \\
\hline$\boxplus \mathrm{Jul}$ & 3 & 2 \\
\hline$\exists$ Aug & 18 & 11 \\
\hline$\exists$ Sep & 9 & 7 \\
\hline $\pm 0 \mathrm{ct}$ & 12 & 10 \\
\hline$\exists \mathrm{Nov}$ & 2 & 0 \\
\hline$₫$ Dec & 7 & 7 \\
\hline Grand Tota & 274 & 136 \\
\hline
\end{tabular}

Fig. 10. Fracture Analysis 1-Power Fracture

\section{A. Temporary Action}

- We find alternate solution at low cost, until to change the domestic power to Industrial [6]

\section{B. Corrective Action}

- Approvel request forward to central equipment modification team for what are the change we plan and how to implemantation and proposal changed request.

- Classified the machine circuit such as Commend circuit and power circuit and we focus on commend circuit because of power consumption is very low.

- Commend circuit, take-up, FT unit are controlled by uninterrupted power.

Figure 11 and Figure 12 represents the fractureanalysis 2 and Prioritization of Matrix

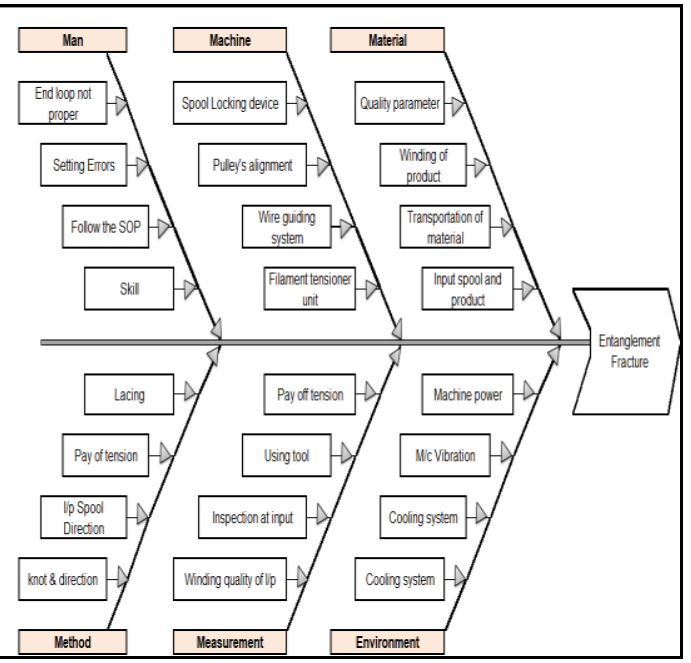

Fig. 11. Fracture Analysis 2-Entanglement Fracture 


\begin{tabular}{|c|c|c|c|c|c|}
\hline \multirow[b]{2}{*}{$\begin{array}{l}\text { Type of } \\
6 \text { GII }\end{array}$} & \multicolumn{5}{|c|}{ Prioritization of Matrix } \\
\hline & Calses & Validation & Low & Medium & High \\
\hline \multirow{4}{*}{ Man } & Skill & Skilled operatior hardled to the machine and fracture found inal Shitt & $x$ & & \\
\hline & Follow he SOP & Inout bading direction / Iacing knot appearance are checked \& found Ok & $x$ & & \\
\hline & Setting Erors & Pay off Take up Tension/MMI seting / Dance am Gap have in as pers seting chart & $x$ & & \\
\hline & End bop not proper & verified unili l dayin al prodiced spool and found innomal & $x$ & & \\
\hline \multirow{6}{*}{ Machine } & \multirow{2}{*}{ Filament tensioner unit } & 1.Breake disc / Tension sporings shat tíndentaion pin have good condition & $x$ & & \\
\hline & & 2.Break bet//Spacerer/Bett locking pin are found damaye condition & & $x$ & \\
\hline & \multirow{2}{*}{ Wie guiding system } & 1.0uter \& Imer Guiding pulleys sare found ok & & $x$ & \\
\hline & & 2. Reversing wheel at 4001 \& $4004 / \mathrm{FT}$ G.unhel beaing found wear out & & $x$ & \\
\hline & Pulleys alignment & Pulleys salgamment are checked \& found ok & & $x$ & \\
\hline & Spool Locking device & Spool hoddersisat//pin are found ok & $x$ & & \\
\hline \multirow{4}{*}{ Material } & Input spool and product & Input spool are produced from Shx 1009, 1010, 1011, 1012 & $x$ & & \\
\hline & Transportation of material & Trolley surface \&Spool liange/ Surtace condition found ok & $x$ & & \\
\hline & Winding of product & Winding checked \& ok found in flat winding & & $x$ & \\
\hline & Qualiyparameter & 100\% inspection of Diameter i Ovality visual parameter and found ok & $x$ & & \\
\hline \multirow{4}{*}{ Method } & Lacing & All Lacing found in a s per procedure & & $x$ & \\
\hline & Payof tension & Pay off tension setting SOP & & $x$ & \\
\hline & IVpspool Diretion & Input spool direction physially cherexted found ok & & $x$ & \\
\hline & knot \& direction & Knot are checked and found all in a s per Procedure & $x$ & & \\
\hline \multirow{4}{*}{ leasuremen } & Pay off tension & Pay off tension checked and found Outer $=400 \mathrm{G}$ and imer $600 \mathrm{G}$ & & $x$ & \\
\hline & Using tool & Arca meter and hasshimith meter are calibrated and arca range $1 \mathrm{~kg}$ wsed & & $x$ & \\
\hline & inilinspetion a tinput & Filament damagee serration / Visual inspection are checked and found ok & & $x$ & \\
\hline & \begin{tabular}{|l}
$\begin{array}{l}\text { Winding gualityo finput } \\
\text { spool }\end{array}$ \\
\end{tabular} & 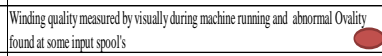 & & & $x$ \\
\hline \multirow{4}{*}{ Invirommen } & Machine power & Eb power fluctuation and unplanned power cut occurred ninimum $1 /$ mathinemonoth & & & $x$ \\
\hline & Mc Vibration & Machine vibrations checked SHX machine and Found BF 2 machine found ok, & & $x$ & \\
\hline & Mc Temperature & SHX \& Bf2 Machine temperature have < 52 degree at Crade \& Torsion shaft & $x$ & & \\
\hline & Cooling system & Water cooling system used and found ok & $x$ & & \\
\hline
\end{tabular}

Fig. 12. Prioritization of Matrix

Figure 13 shows the Potential Causes validation \& before and after

\begin{tabular}{|c|c|c|c|c|c|c|c|c|c|c|}
\hline \multirow[b]{2}{*}{ S.no } & \multirow{2}{*}{$\begin{array}{c}\text { Input Spool Winding Qualily } \\
\text { Causes }\end{array}$} & \multirow[b]{2}{*}{ Melhod } & \multicolumn{4}{|c|}{ Cause valithation at Before } & \multicolumn{4}{|c|}{ Cause validation at After project } \\
\hline & & & SHX 1009 & SHX 1010 & SHX 1011 & SHX 1012 & SHX 1009 & SHX 1010 & SHX 1011 & SHX 1012 \\
\hline 1 & Controller at Slave A093 & Visually & Beck 10 & Bec 10 & Bec 10 & Bec 10 & Beck 10 & Bec 10 & Bec 10 & Bee 10 \\
\hline 2 & Controller at Master A 090 & Visually & Bec 100 & Bec 100 & Bec 100 & Bec 100 & Bec 100 & Bec 100 & Bec 100 & Bec 100 \\
\hline 3 & Program verion & HIM & $\mathrm{NDE}-2.5$ & NDE -2.5 & NDE-2.5 & NDE- 2.5 & $\mathrm{NDE}-2.5$ & NDE 2.25 & NDE - 2.5 & NDE-2.5 \\
\hline 5 & Machine speed in M/mint & нім & 900 & 900 & 900 & 900 & 900 & 900 & 900 & 900 \\
\hline 6 & Winding pitch & нім & 0.8 & 0.8 & 0.8 & 0.8 & 0.8 & 0.8 & 0.8 & 0.8 \\
\hline 7 & $\left(\begin{array}{l}\text { Take up tensin } \\
\text { Accept Range 750G to 850G) }\end{array}\right.$ & $\begin{array}{l}\text { DTMB } \\
2000 @ .2\end{array}$ & 889 & 914 & 804 & 930 & 800 & 780 & 804 & 810 \\
\hline 8 & Dancer fluctuation & Visually & Nomal & Nomal & Nomal & \begin{tabular}{|l|} 
Normal \\
\end{tabular} & Normal & Nomal & Nomal & Nomal \\
\hline 9 & \begin{tabular}{|l} 
Machine Vibration at Running \\
Length \\
Full length/spoos=170830M) \\
\end{tabular} & нім & 25000 & 150000 & 88000 & 81000 & 25000 & 150000 & 88000 & 81000 \\
\hline 10 & \begin{tabular}{|l} 
Macchine Vibration (MWS) \\
(Accept Range <.3.0 10 4.5)
\end{tabular} & $\begin{array}{l}\text { vaib. } \\
\text { Meter }\end{array}$ & $\mid 4.8$ to $6.1 \mid$ & 3.7 to 5.8 & 2.7104 .8 & 3.310 .5 .2 & 2.1104 .0 & 2.403 .8 & 2.0 to 4.1 & 2.7104 .3 \\
\hline 11 & Bell Condition & Visually & ok & ok & wear & ok & ok & ok & wear & ok \\
\hline 12 & Bett tension in Hz $(65 \pm 5)$ & Fry.Meter & 52.5 & 67.5 & 57.2 & 50.5 & 62.2 & 65.8 & 649 & 60.9 \\
\hline 13 & Spool shaff Condition & Visually & ok & ok & ok & ok & ok & ok & ok & ok \\
\hline 14 & $\begin{array}{l}\text { Take up Shaft Runout in MM at } \\
\text { spool entry (Accept Range < } \\
\text { o.15mm without load) }\end{array}$ & Dial Gauge & 0.24 & 0.21 & 0.19 & 0.26 & 0.11 & 0.12 & 0.12 & 0.1 \\
\hline 15 & 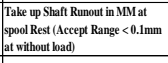 & Dial Gauge & 0.12 & 0.11 & 0.08 & 0.11 & 0.07 & 0.09 & 0.08 & 0.07 \\
\hline 16 & Winding condition @ Full spool & Visually & Flat & Flat & Flat & Flat & Flat & Flat & Flat & Flat \\
\hline 17 & $\begin{array}{l}\text { Winding condition during Spool } \\
\text { unming @ E BF2 }\end{array}$ & Visually & Oral & Oval & Oval & Oval & ok & ok & ok & ok \\
\hline 18 & WS 50 Spool condition & Visually & ${ }^{0 k}$ & ${ }_{\mathrm{ok}}$ & ${ }^{0 \mathrm{~K}}$ & ${ }^{0 \mathrm{~K}}$ & ${ }^{0 \mathrm{~K}}$ & ${ }^{\circ} \mathrm{k}$ & ok & ok \\
\hline 19 & Travers limit sensor & M.Meter & No Noise & \begin{tabular}{|l|l|} 
No Noise \\
\end{tabular} & \begin{tabular}{|l|} 
No Noise \\
\end{tabular} & \begin{tabular}{|l|l|} 
No Noise & \\
\end{tabular} & No Noise & \begin{tabular}{|l|l|} 
No Noise \\
\end{tabular} & \begin{tabular}{|l|} 
No Noise \\
\end{tabular} & No Noise \\
\hline
\end{tabular}

Fig. 13. Potential Causes validation $\&$ before and after

\section{Improvements}

Figure 14 and figure 15 before and after modification and correction as

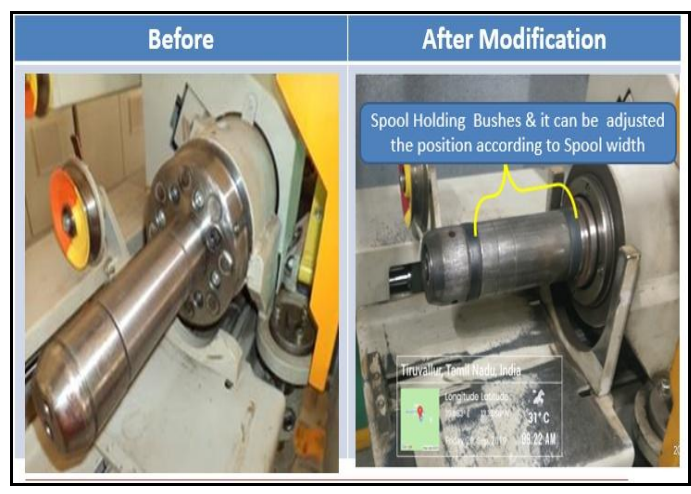

Fig. 14. Befor and After modificationtion

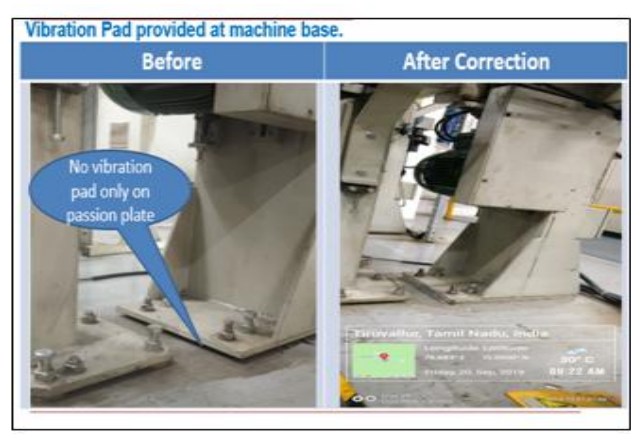

Fig. 15. Befor and After Correction

Figure 16 and figure 17 shows the Better improver the our fracture per ton trends \& Results,

Better improvement we faced from input change over time on 3 wire bunching process

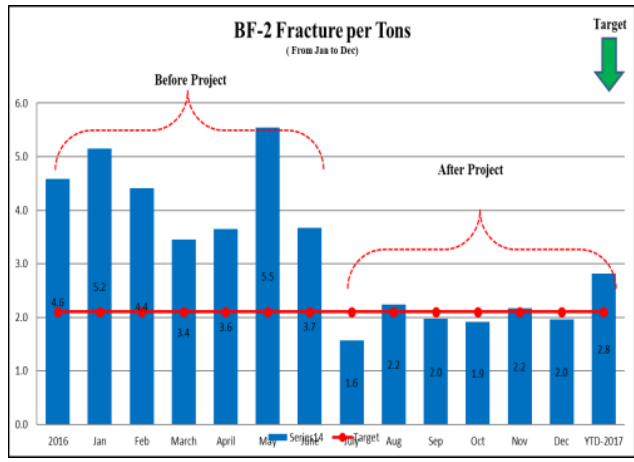

Fig. 16. BF-2 Fracture per Tons

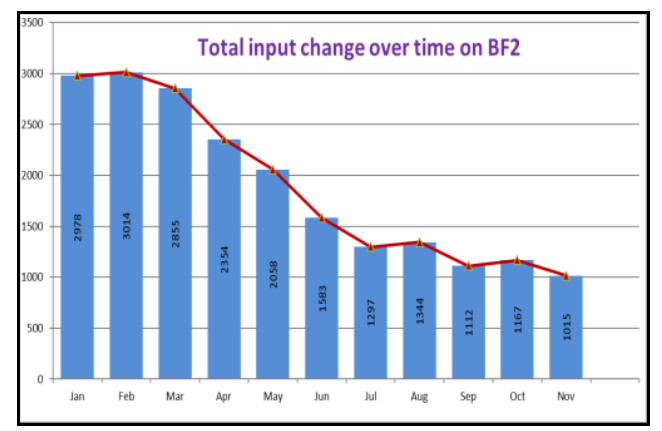

Fig. 17. Total input change over time on BF-2

Published By:

Blue Eyes Intelligence Engineering

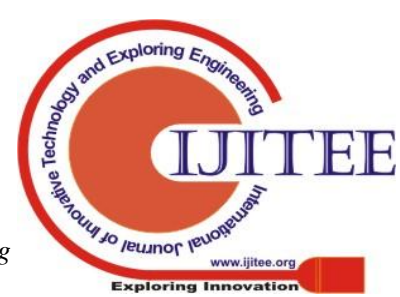




\section{CONCLUSION}

This task work lead us a great exposure and awareness, to utilize our insight. A great deal of useful information is acquired in terms of reduction fracturein steel cord manufacturing process

Power fracture- Power Interruptions action taken for this particular problem **Machine input powers of control power $(24 \mathrm{~V}), 230 \mathrm{~V}$ and Maine power $(440 \mathrm{~V}$ devices are connected with relay \& uninterrupted power source.

1. In such way of to controlled irregular stops of machine while powerinterrupted.

2. Minimum power consumption and investment cost.

3. Executed in All BF2, BFM, HKM machine.result of power fracture.Entanglement fracture or winding issueTake-up spool shaft modification on Shxuing machine. Action taken for this problem Wire spool shaft was changed in all Shxuing machine and found Shaft run-out was minimized and also noise level unsafe risk are reduced.result $18 \%$ reduced from overall fracture and saving realised from actual.Machine vibration - Action taken Vibration pad ( High impact rubber pad) was provided in machine base with position plate. Its lead to reduce the winding pitch variation. Result for this problem $5 \%$ reduced from overall fracture and saving realised from actual. Input Change over time- Action taken for the problem Better improvement we faced from input change over time on 3 wire bunching process as a result $50 \%$ of change over time is reduced. from 2800 Minutes to 1400 Minutes reduced per month.

\section{REFERENCES}

1. Y. OKI, "Bulletin of The Iron and Steel Institute of Japan”, 8(9), Sep.2003, pp.627-632.

2. Y. Yamada et al., R\&D Kobe Steel Engineering Reports, 36(4), 1986, p.71.

3. R. Kruzel, M. Suliga, "The impact of the steel cord construction of its decline of breaking force after fatigue test in bidirectional bending conditions", Metalurgija 54(1), 2015, 214-216.

4. N.A. McPherson, A. McLean, Continuous Casting: Non-Metallic Inclusions in Continuously Cast Steel. Iron \& Steel Society; Warrendale, PA, USA: 1995.

5. L. J. Chen ,W. Q. Chen, Y. Hu, Z. P.Chen ,Y. T. Xu ,W. Yan," Effects of $\mathrm{K} 2 \mathrm{CO} 3$ addition on inclusions in high-carbon steel for saw wire". High Temperature Materials and Processes, 37(8), Agu.2018, pp.701-709.

6. E. M. Taleff, J. J. Lewandowski, B. Pourladian, “ Microstructure-property relationships in pearlitic eutectoid and hypereutectoid carbon steels", Jom, 54(7), Jul.2002, pp.25-30.

7. H. Y.He, "Master's Thesis, University of Science and Technology Beijing; Beijing", Study on Prodution Technology of High Carbon Steel, Dec. 2010

\section{AUTHORS PROFILE}

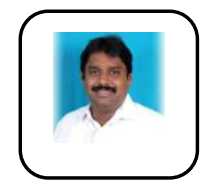

L.Prabhu, Assoc. Professor Department of Mechanical Engineering Aarupadai Veedu Institute of Technology Vinayaka Mission Research Foundation prabhu@avit.ac.in. 